\title{
Letramento hipertextual: por uma análise e redefinição do conceito
}

\section{Hypertextual literacy: for its concept analysis and redefinition}

Regina Cláudia Pinheiro*

Universidade Estadual do Ceará

Fortaleza - Ceará / Brasil

Júlio Araújo**

Universidade Federal do Ceará

Fortaleza - Ceará / Brasil

RESUMO: Neste artigo refletimos sobre a emergência de um conceito de letramento hipertextual a partir da descrição de práticas de letramento realizadas por sujeitos na elaboração de material didático para um curso on-line. A partir das ideias sobre letramento hipertextual de Bolter (1998) e letramentos múltiplos de Semalli (2001), realizamos um estudo de caso no qual acompanhamos a elaboração de material didático para o ensino on-line. Os resultados nos mostraram que, para exercer práticas de letramento hipertextual, os usuários necessitam entrelaçar múltiplos letramentos, tais como os letramentos tradicional, visual, informático e informacional. Nesse sentido, defendemos que o conceito de letramento hipertextual deve ser considerado uma categoria maior, que se realiza a partir da conexão entre múltiplos letramentos. PALAVRAS-CHAVE: letramento hipertextual, novos letramentos, elaboração de material didático.

ABSTRACT: This paper brings a discussion about the emergence of a concept of hypertextual analysis, which starts with the description of the literacy practices carried out by subjects while designing teaching materials for online education. From the ideas about hypertextual literacy in Bolter (1998), and multiple literacies in Semalli (2001), we apply a methodology defined as a case study in which we followed the steps in the elaboration of teaching materials for online education. The results show that, in order to carry out practices in hypertextual literacy, multiple literacies must be intertwined by the users, such as the traditional, visual, computing and informational literacies. In this light, the concept of hypertextual literacy must be considered as a higher category which is realized from the connection between multiple literacies.

KEYWORDS: hypertextual literacy, new literacies, development of instructional materials.

\footnotetext{
* rclaudiap@yahoo.com.br

**araujo.ufc@gmail.com
} 


\section{Introdução}

$\mathrm{O}(\mathrm{s})$ conceito(s) de letramento(s), desde o seu nascituro, têm suscitado muitos questionamentos e, atualmente, com a inserção das tecnologias digitais de informação e comunicação, os estudos relativos a esse assunto têm se multiplicado devido às novas práticas sociais que essas tecnologias possibilitaram. Essa diversidade de conceitos e trabalhos, aliada às diversas transformações e práticas sociais para acesso à informação e comunicação, tornam o assunto complexo e possibilitaram a caracterização dos letramentos. Nesse sentido, com relação às práticas sociais advindas das tecnologias digitais, muitos são os termos e conceitos surgidos, tais como letramento tecnológico, letramento digital e letramento computacional. Esses termos advêm de práticas semelhantes e seus conceitos, muitas vezes, ancoram-se somente nos usos que se fazem com a mediação das tecnologias de informação e comunicação, desconsiderando que, nessas interaçōes, são necessárias outras habilidades demandadas por outros tipos de letramentos. Refletindo sobre essas questóes, surgiu a pergunta que orienta este artigo: Quais letramentos são demandados nas interações mediadas pelas tecnologias de informação e comunicação e que termo contempla todos esses letramentos?

Em uma tentativa de respondermos a essas questōes, inicialmente, nos debruçamos sobre o trabalho de Jay David Bolter (1998), o qual caracteriza o letramento hipertextual, e fizemos reflexóes acerca da justificativa que o autor apresenta para a caracterização desse termo. Nessas reflexões, chegamos à conclusão de que o letramento hipertextual, tal como exposto por Bolter (1998), já não acolhe as diversas práticas de linguagens exercidas pelos usuários das tecnologias de informação e comunicação atualmente. Em seguida, refletimos sobre práticas advindas do mundo on-line, com base em autores que consideram o conceito de letramento pluralizado. Posteriormente, apresentamos a metodologia empreendida para a construção dos dados e a análise desses dados que nos confirmam a presença de diversos letramentos no exercício de elaboração de material didático para o ensino on-line. Nas consideraçôes finais, refletimos sobre a necessidade de um conceito que contemple todas essas práticas.

\section{O conceito de letramento hipertextual}

O termo letramento hipertextual já apareceu na literatura em artigo de Bolter (1998), porém, esta expressão não ganhou audiência nos estudos 
acadêmicos brasileiros. Atualmente, o termo cunhado pelo autor não contempla mais as características do hipertexto digital, pois estas já foram sobrepostas por outras ou mesmo refutadas, conforme se apresenta a seguir. Sendo assim, com base nas transformaçōes tecnológicas e, consequentemente, sociais, afirmamos com Brian V. Street (2003) que as pesquisas etnográficas têm possibilitado aos pesquisadores cunhar novos termos e dar novos significados a novos conceitos. Nesses termos, refletindo através de análise bibliográfica e de material empírico, percebemos que o letramento hipertextual necessita de um conceito que se adapte às exigências atuais.

A justificativa para caracterizar o letramento como hipertextual, em Bolter (1998), deu-se devido à inserção do computador nas sociedades e seu grande impacto nas teorias e práticas educacionais, fazendo, assim, repensar a noção de texto. Deste modo, o autor reflete sobre "como o computador está complicando a natureza do texto e, portanto, a questão do letramento [...], já introduzida pelos estruturalistas" (BOLTER, 1998, p. 3, tradução nossa). Um fator que evidencia essa complicação é a relação imagem-texto, cujo entrelaçamento faz o autor questionar se há dois letramentos (verbal e visual) ou somente um.

Neste sentido, o autor toma como base para caracterizar o letramento hipertextual três aspectos, a saber: a relação entre as linguagens verbal e visual, a multilinearidade e a nova relação entre autor-texto-leitor.

Sobre a relação entre texto e imagem, Bolter afirma que, há duas décadas, ${ }^{1}$ as ilustraçôes tinham importância secundária e eram consideradas arte. No entanto, ele questiona essa suposição, afirmando que se faz necessário entender melhor essas noçôes, pois, além das possibilidades infinitas de leitura, a web também proporciona imagens estáticas, animação e vídeos em associação com as páginas escritas. Para o pesquisador, as imagens eram importantes somente para certos gêneros de livros impressos, como atlas, anatomias, enciclopédias etc. Porém, no século XX, o cinema e a televisão desafiaram o domínio do texto escrito, passando os cidadãos a viver numa cultura visual. O autor questiona se a comunicação eletrônica será construída como uma extensão da mídia impressa ou como uma nova mídia visual.

Após mais de uma década da publicação do texto do autor, percebemos que o mundo impresso e o visual se completam em mídias que se convergem

\footnotetext{
${ }^{1}$ Lembramos que a publicação citada é de 1998, portanto, o autor se refere a duas décadas anteriores a este ano.
} 
no ciberespaço. ${ }^{2}$ Sendo assim, os cidadãos vivem numa cultura de convergência verbo-visual, independentemente de estarem conectados à internet, pois outros meios, como a televisão, o celular, sobretudo, os smartphones e os tablets etc., incorporaram essa cultura.

Com relação à multilinearidade, segundo o autor, o hipertexto se configura sob a forma de links, tornando-o multilinear e "radicalmente instável e imprevisível de uma forma na qual o texto impresso não é" (BOLTER, 1998, p. 5, tradução nossa). Desse modo, Bolter discorda de muitos teóricos, tais como Peter W. Foltz (1996), Luiz Antônio Marcuschi (2000) e George Landow (2002), que consideram o hipertexto não linear. Para Bolter, "os hipertextos não são não-lineares, mas sim multilineares” (BOLTER, 1998, p. 5, tradução nossa), igualmente a muitas publicaçõos impressas, como jornais, revistas e dicionários. Entretanto, há, nos textos impressos, uma ordem na qual as páginas são colocadas. O pesquisador também afirma que um hipertexto também pode ser construído em um livro impresso ou mesmo um hipertexto eletrônico pode ser completamente linear com um link no final de cada unidade direcionando-o para a próxima unidade.

Outra característica apresentada por Bolter é a nova relação entre autor, texto e leitor cujo elo se diferencia da relação com os textos impressos que são reproduzidos e distribuídos para uma audiência de leitores relativamente passivos, pois eles "podem examinar o texto do autor e aprovar ou desaprovar, mas não podem interferir de forma nenhuma no significado" (BOLTER, 1998, p. 6, tradução nossa), o que confere ao autor um forte status cultural. Em outro sentido, conforme a mesma obra, o hipertexto aniquila a autoridade do autor, tornando mais igualitária sua relação com o leitor, pois este interfere mais no texto, tornando-se uma espécie de autor. Apesar de anunciar uma passividade relativa, o pesquisador reconhece que as pesquisas educacionais consideram a leitura como um processo ativo de construção de significado porque os leitores relacionam o sentido do texto aos seus conhecimentos prévios.

Sabemos, no entanto, que há hipertextos em que essa nova relação anunciada por Bolter não é possível, principalmente, aqueles impressos e em CD-ROM que o referido pesquisador definiu como hipertexto. Porém, há os hipertextos que se caracterizam pela colaboração e participação dos internautas,

\footnotetext{
${ }^{2}$ Segundo David Crystal, o termo ciberespaço "foi cunhado para capturar a ideia de um mundo de informação, presente ou possível, em forma digital" (CRYSTAL, 2005, p. 77).
} 
possibilitando uma autoria coletiva. Assim, se somente esses hipertextos mudam a relação autor-texto-leitor e a antiga relação é característica também de textos impressos, podemos considerar que, sobre o aspecto da nova relação autor-texto-leitor, essa caracterização de Bolter não diz respeito a qualquer hipertexto.

Para caracterizar o letramento hipertextual, Bolter (1998) considera o hipertexto como uma tecnologia que pode estar conectada à internet, estar offline ou, ainda, estar impressa. No entanto, o autor não apresenta uma definição clara para o termo letramento hipertextual e deixa para o leitor a tarefa de inferir seu conceito com base na caracterização que faz da expressão levando em consideração os três aspectos citados anteriormente.

No entanto, sem desmerecer o espraiamento do hipertexto para além do virtual, o recorte realizado neste artigo sinaliza para um conceito que considera o hipertexto unicamente em sua dimensão digital. Nossa decisão é amparada pela perspectiva dos novos estudos de letramento (STREET [1984]; BARTON; HAMILTON; IVANIC [2000]), que defendem a assimilação dos usos da escrita e da leitura como atividades sempre situadas, espacial e historicamente.

Com base nessa perspectiva teórica, o hipertexto será visto aqui como uma tecnologia on-line e o letramento hipertextual, portanto, uma prática que inclui diversas habilidades de leitura e escrita multimodais a partir das tecnologias digitais. Porém, concordamos com o autor quando ele afirma que a leitura na tela requer habilidades de descobrir relações complexas entre páginas, próprias do hipertexto, e habilidades convencionais exigidas em textos lineares. Regina C. Pinheiro (2005) também constatou que, na leitura de hipertexto, os leitores lançam mão de estratégias utilizadas em textos impressos e outras próprias da leitura hipertextual. Sendo assim, o letramento hipertextual requer habilidades do letramento verbal, considerado por Magda Soares (2000) como as práticas sociais de leitura e de escrita, exercidas pelos indivíduos inseridos em sociedades letradas, mas também exige outras habilidades desses indivíduos.

Tentamos indicar até aqui que os argumentos apresentados por Bolter (1998), para justificar a necessidade de um letramento hipertextual, não contemplam o material existente na internet do século XXI. Sabemos que, com o advento da web 2.0, muitas possibilidades foram incorporadas ao mundo virtual, as quais não podíamos encontrar na década de 1990, período em que Bolter cunhou o termo, conforme veremos subsequentemente. 


\section{Novas práticas no mundo on-line: um entrelaçamento de letramentos}

Os estudos sobre letramentos têm se intensificado com o advento das tecnologias de informação e comunicação nas sociedades, devido às transformações ocorridas nas práticas sociais dos indivíduos, especialmente, aquelas que são mediadas por essas tecnologias. Nesse sentido, muitos autores consideram que o(s) conceito(s) de letramento(s), adaptável(is) às transformaçôes sociais, se modificou(aram) para atender às novas demandas.

Refletindo sobre a necessidade de considerar o conceito de letramento como uma compreensão pluralizada, Mary Elizabeth Cerutti-Rizzatti revela que a escrita deve ser considerada em diferentes espaços e tempos nos quais circula, "envolvendo sujeitos situados espacial e historicamente" (CERUTTIRIZZATTI, 2009, p. 5). No entanto, a autora, tecendo consideraçôes sobre o fato de a escrita ser estudada onde "se concretiza e em benefício de quem se faz instrumento", critica as qualificaçóes que se atribuem aos letramentos, tais como letramentos eletrônicos, letramentos ecológicos, letramentos matemáticos etc. Sua argumentação recai no fato de determinadas adjetivações dadas aos letramentos não contemplarem "a interação com base no signo verbal escrito", significando, para a pesquisadora, que o conceito de letramento deve ser pautado somente pela escrita. Refletindo sobre as consideraçóes da autora, podemos perceber algum ranço de uma concepção tradicional de letramento e, consequentemente, de leitura, segundo a qual somente o signo escrito pode possibilitar conhecimento. Considerando as transformações sociais, nas quais o texto visual, por exemplo, possibilita uma importante forma de aprendizagem e nos faz ler o mundo, estando, muitas vezes, complementando o texto escrito, percebemos um equívoco nas palavras da pesquisadora, especialmente, quando declara que, "em nossa compreensão, para tratarmos de letramento, o signo verbal escrito tem de estar presente de modo prevalecente" (CERUTTI-RIZZATTI, 2009, p. 5). Assim, por discordarmos da autora com relação à necessidade da presença da escrita nos estudos de letramento, apresentamos, neste trabalho, alguns autores que consideram esse conceito plural, tendo em conta que ele não se limita somente às práticas sociais com a escrita.

Concordando com Ladislaus M. Semalli (2001), acreditamos que, nesse momento de transição, muitos conceitos, especialmente aqueles ligados às transformações, são incompletos, permitindo-nos perceber que não podemos reivindicar uma definição de letramento que contemple todas as práticas, pois as rápidas mudanças tecnológicas transformam as práticas sociais ao longo do 
tempo das culturas. Nesse sentido, selecionamos, para este estudo, a definição de Francisco S. Cavalcante Junior, para quem letramento(s) é(são) concebido(s) como "um processo de leitura diária do mundo - o mundo interior e exterior de cada ser humano - e a composição desses mundos através do uso de múltiplas linguagens de (re)presentação de sentidos", tais como a sonora, a corporal, a literária, a espacial, a espiritual, a visual e a multiforme (CAVALCANTE JUNIOR, 2003, p. 26).

Ainda Semalli (2001) considera os novos letramentos como aquelas práticas sociais que surgiram na era pós-tipográfica, que "marca mudanças culturais e intelectuais na forma como a informação é concebida, comunicada e recuperada”, desestabilizando as concepções anteriores de letramento (SEMALLI, 2001, tradução nossa). O referido autor, ao contrário de CeruttiRizzatti (2009), defende a divisão dos letramentos, argumentando que cada tipo demanda dos usuários competências particulares diferenciadas e com práticas específicas. Segundo ele, para uma pessoa ser letrada no mundo pós-moderno, necessita adquirir competências variadas envolvendo diversos letramentos que se sobrepóem. Assim, o autor define alguns dos letramentos mais citados:

- Letramento informático: habilidades de uso com a linguagem do computador, que incluem competências referentes às representações visuais, multimidiáticas, interativas e hipertextuais;

- Letramento informacional: criação, difusão e recuperação de informações de forma rápida, reconhecendo aquela que é necessária, localizando-a, avaliando-a e usando-a de forma eficaz;

- Letramento midiático: capacidade de acessar, experimentar, avaliar e produzir produtos de mídia que são utilizados para representar eventos reais;

- Letramento televisivo: capacidade de ler e interpretar mensagens televisivas;

- Letramento visual: "múltiplas habilidades de ler, ver, compreender, avaliar e interpretar os textos visuais, incluindo artefatos, imagens, desenhos ou pinturas que representam um evento, ideia ou emoção". (SEMALLI, 2001, tradução nossa).

As definições apresentadas confirmam a declaração do autor de que "chegou a hora de ampliar os cânones da educação tradicional e do currículo para incluir as tecnologias de expansão da televisão, cinema, vídeo e computadores" (SEMALLI, 2001, tradução nossa). É importante também 
frisar o entendimento do pesquisador na relação entre os diversos letramentos, quando ele reconhece que há uma sobreposição das definiç̧óes de termos como letramento midiático, letramento informático e letramento visual.

Nesse sentido, para compreendermos o letramento hipertextual, devemos considerar que não somente a escrita é parte essencial para fazer sentido das situações em que as tecnologias digitais são o meio através do qual os indivíduos interagem. Os eventos de letramento ocorridos através dessas tecnologias se constituem de várias modalidades, como a sonora e a visual, que, a depender das cenas de letramento, coocorrem em níveis distintos de importância (LEMKE, 2002). Na maioria das "salas de aula virtuais", por exemplo, a escrita é a modalidade preponderante na construção do sentido entre os que interagem ali. Porém, ao postar ou baixar o clipe de uma música ou o vídeo de uma palestra no YouTube, o som e a imagem passam a ser as modalidades mais importantes para que o sentido se deixe construir pelo utente dessa tecnologia.

\section{Metodologia}

Para a realização deste trabalho, contamos com dados retirados de um estudo de caso, ainda em andamento no Programa de Pós-Graduação em Linguística da UFC. Os dados advêm de um material didático on-line elaborado para duas disciplinas do Curso de Letras Semipresencial da Universidade Federal do Ceará (UFC Virtual). Para otimizar os usos desses dados, utilizamos ainda trechos de entrevistas realizadas com professores elaboradores desse material didático. Nosso intento foi flagrar indícios que sinalizassem para os diversos letramentos praticados pelos nossos informantes, ao interagir com seus alunos, através de hipertextos.

O material didático elaborado para as disciplinas dos cursos de graduação semipresenciais ofertados pelo Instituto Virtual da Universidade Federal do Ceará fica disponibilizado em um Ambiente Virtual de Aprendizagem doravante AVA - da própria universidade, denominado Solar, através do qual acontecem as aulas on-line. Para a produção desses materiais, os participantes praticam eventos de letramentos que, de alguma maneira, são mediados pelas tecnologias de informação e comunicação e pela internet.

As entrevistas concedidas para geração dos dados são de professores que elaboraram material didático para as licenciaturas em Letras - Português e Letras - Espanhol, sendo selecionadas três disciplinas que estavam sendo planejadas pelos docentes no período da coleta de dados da referida pesquisa. 
As disciplinas mencionadas foram de áreas distintas, sendo uma da Linguística, outra da Literatura e a terceira do Espanhol.

A seguir, explicitaremos quem são os sujeitos que nos concederam as entrevistas.

\section{Os sujeitos da pesquisa}

Os sujeitos desta pesquisa foram professores conteudistas (PROF), que elaboram o material do curso, e equipe de transição didática (TD), responsável pela transformação desse material em formato web.

O primeiro grupo tem como participantes os professores conteudistas das disciplinas que, geralmente, pertencem ao quadro de docentes efetivos de instituição de ensino superior, preferencialmente da Universidade Federal do Ceará, e são convidados para elaborar o conteúdo das disciplinas de sua competência. Como parte de seu trabalho, precisam elaborar material didático, planejar e acompanhar a execução da disciplina, que é ministrada por sua equipe de tutores. O referido material é transposto para um formato web pela equipe de transição didática e disponibilizado na plataforma virtual Solar, na qual os alunos poderão acessá-lo e discuti-lo, através de questōes referentes às disciplinas, com o referido professor, com o tutor e com os demais alunos. Das áreas de Literatura e Espanhol, trabalhamos com o professor de Estágio em Literaturas de Língua Portuguesa e de Fonologia do Espanhol II, respectivamente. Com relação à disciplina da área de Linguística, participou desta pesquisa o professor de Estágio em Análise Linguística.

O segundo grupo é formado por profissionais que compõem a equipe de transição didática do Instituto UFC Virtual. São eles os responsáveis pela transformação do material didático elaborado pelo professor conteudista em um formato web, bem como pela disponibilização do produto final na plataforma Solar. Optamos por trabalhar também com esses profissionais porque eles não apenas ajustam o material para a hipertextualização digital do conteúdo elaborado pelos professores conteudistas, como também acabam influenciando esses professores durante a elaboração dos conteúdos, em função das constantes trocas de $e$-mails entre ambos.

\section{Os instrumentos para geração de dados}

Com o objetivo de chegarmos aos dados que nos possibilitarão flagrar letramentos diversos, nas práticas sociais exercidas pelos sujeitos deste estudo, selecionamos a entrevista semiestruturada e a seleção de um corpus, que 
compreende o material didático de duas disciplinas disponibilizadas no AVA Solar, do Curso de Licenciatura em Letras - Português.

A entrevista semiestruturada, na qual o pesquisador estabelece um roteiro de perguntas a serem respondidas pelo pesquisado, mas deixa espaço para outros questionamentos no decorrer do processo, foi realizada com todos os participantes dos dois grupos e teve como objetivo captar as diferentes perspectivas sobre os letramentos demandados na interação com hipertextos. A gravação desse momento foi registrada através do programa Audacity, um software gratuito e de fácil manuseio que grava e reproduz sons com um microfone acoplado ao computador. As entrevistas foram realizadas nos meses de junho e julho de 2011 em locais escolhidos pelos participantes e, posteriormente, foram transcritas a fim de que pudessem ser usadas nas análises.

Além das entrevistas, coletamos ainda exemplares de um material elaborado para disciplinas do Curso de Letras - Português, a fim de localizarmos práticas que demandam letramentos diversos. As disciplinas selecionadas para coleta desse material foram Linguística Textual e Gêneros Textuais e Ensino.

Ao procedermos a um exame, ainda preliminar, dos dados, percebemos um entrecruzamento de letramentos múltiplos subjacente à tarefa de elaborar material didático para o ensino on-line. A figura a seguir se aproxima de como percebemos o letramento hipertextual nos dados.

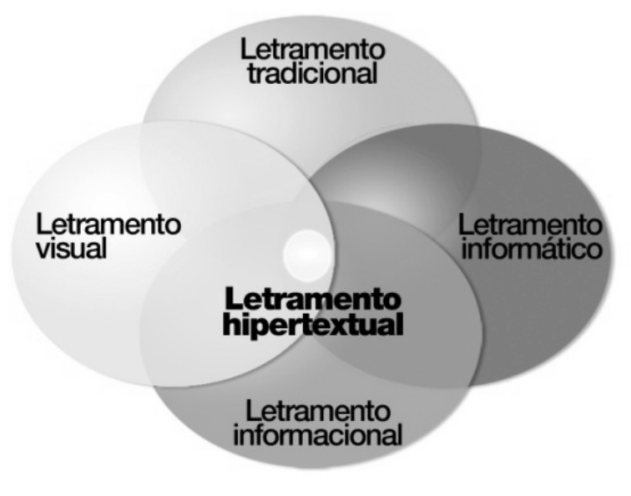

FIGURA 1 - O folheado do letramento hipertextual 
A análise que passaremos a mostrar subsequentemente toma cada um dos tipos de letramento isoladamente apenas para fins didáticos porque eles, na verdade, coocorrem, na concomitância do processo de elaboração dos conteúdos didáticos para o ambiente virtual de aprendizagem.

\section{Análise dos dados}

Nesse item, procuramos analisar excertos da fala dos professores e da equipe de transição didática, separando essa análise em letramento tradicional, visual, tecnológico e informacional. Além do mais, para ilustrar cada tipo de letramento, inserimos exemplares do material didático elaborado, a fim de reafirmamos a necessidade de encetarmos uma discussão que considere um conceito de letramento hipertextual.

\section{Letramento tradicional}

As sociedades modernas demandam dos cidadãos que nelas residem diversas práticas sociais mediadas pela escrita que se intensificaram com o advento das TIC. No entanto, práticas simples, como pegar um ônibus ou pagar uma conta em um caixa eletrônico, podem ser tarefas complicadas para aqueles que têm níveis baixos de letramento tradicional. Neste artigo, estamos considerando letramento tradicional, "o estado ou condição de quem não apenas sabe ler e escrever, mas cultiva e exerce as práticas sociais que usam a escrita" (SOARES, 2000, p. 47).

Na elaboração do material didático para o ensino on-line, percebemos que o texto verbal é muito importante para as práticas dos sujeitos. No entanto, notamos que há uma diferenciação dessas práticas quando elas se materializam em gêneros que emergiram com as tecnologias digitais e são utilizadas para interagir em programas específicos da informática. Esses casos comprovam que uma única concepção de letramento não seria suficiente para contemplar as mudanças ocorridas com o advento das tecnologias de informática no trabalho de elaboração de conteúdos didáticos para cursos que acontecem em um sistema semipresencial. Por outro lado, julgamos relevante ressaltar que o letramento tradicional continua a ser exigido para efetivação de outras práticas letradas emergentes das tecnologias digitais, havendo, desse modo, um entrelaçamento de letramentos nesse contexto.

Os exemplos a seguir demonstram como os usuários dos cursos a distância necessitam de práticas de letramento tradicional. Nos exemplos (1) 
e (4), percebemos a necessidade de leitura e escrita, quando há a substituição da fala do professor em texto escrito e as atividades que os alunos devem praticar através de chats, fóruns, portfólios etc. Os exemplos (2) e (3) demonstram que o conteúdo para web deve ser conciso, mas os discentes devem aprofundar seus conhecimentos através de material de apoio, muitas vezes, disponibilizado no ambiente virtual pelo docente:

1. [...] alguns conteúdos que nós iríamos ministrar em sala de aula falando diretamente para os alunos, nós não temos oportunidade de fazer isso num... digamos... numa situação... remota em que o aluno está em outra rede. Então, quer dizer que aquele conteúdo da aula não se perde, eu apenas dou uma forma escrita pra ele [...] (PROF 1).

2. Os professores já enviam o material bem conciso e bem claro para transmitir o conteúdo (TD 1).

3. $\mathrm{Na}$ aula, é muito importante quando o professor deixa material de apoio... Isso enriquece a aula (TD 1).

4. Aí tem as atividades de portfólio, em que muitas vezes pode ser um trabalho escrito [...] O chat, realmente, [...] só é possível trabalhar na parte escrita... [...] Eu pedia atividades que eles teriam, realmente, que ler e escrever, porque, muitas vezes, eles utilizam esses espaços pra outras coisas, exemplos: usam o chat para conversar como os colegas. Aí, a gente tem sempre que estar puxando, então assim, foi bem... (PROF 2).

Os grifos acima, todos nossos, abalizam a consciência latente entre os professores conteudistas e os membros da equipe de transição didática de que o letramento tradicional é importante e, por isso, é mobilizado na elaboração de conteúdos para subsidiar um curso de graduação em ambiente virtual, pois, o que seria falado numa cena pedagógica presencial, por exemplo, precisa ser escrito no virtual.

No exemplo seguinte (FIG. 2), vemos uma atividade de fórum na qual os alunos discutem um tema sugerido pelo professor. Essa atividade, na modalidade a distância, substitui uma discussão em sala de aula em que alunos e professores estão presentes em um mesmo espaço-tempo. Nos fóruns virtuais, porém, cada participante pode postar de onde estiver e no momento que lhe for conveniente. $\mathrm{O}$ exemplo demonstra a importância do letramento tradicional nesses cursos em que alunos e professores devem transformar o que seria falado presencialmente em texto escrito e se fazer entender através dele. 


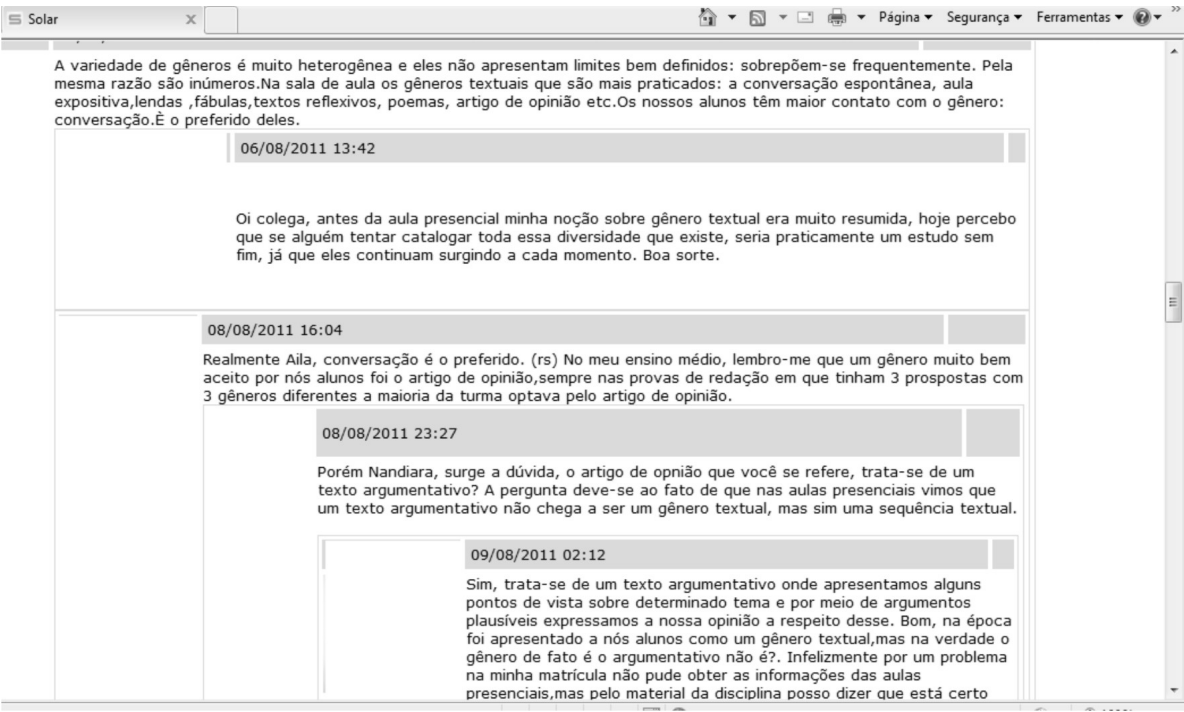

FIGURA 2 - Fórum de discussão, retirado da disciplina Gêneros Textuais e Ensino

Reconhecemos a importância do letramento tradicional para os cursos on-line, especialmente aqueles de áreas de Ciências Humanas e Sociais, porém, concordamos com Semalli (2001), quando afirma que os professores já estão cientes do poder desses letramentos. No entanto, para o autor, o ensino deve considerar tanto os letramentos tradicionais quanto aqueles oriundos das tecnologias multimidiáticas que, muitas vezes, não fazem parte do cotidiano de muitas escolas, mas já compóem a cena pedagógica de cursos on-line. Assim, percebemos que o letramento tradicional é a principal forma de interação nos cursos pesquisados, porém, isso não prescinde a relevância de outros letramentos e habilidades demandados pelo contexto de interação virtual.

\section{Letramento visual}

Percebemos nos dados que, assim como o letramento tradicional, o letramento visual também é muito presente nas práticas dos sujeitos elaboradores de material didático para as disciplinas on-line da plataforma Solar. Refletindo sobre esta constatação, notamos que o letramento visual é tão importante para as práticas de linguagem nas sociedades modernas quanto qualquer outro letramento, haja vista as informações estarem repletas de imagens, sendo alguns textos, exclusivamente, visuais. 
Desse modo, concordamos com Elizabeth Daley quando afirma "que tal linguagem pode ter diferenças claras e até vantagens em relação à linguagem impressa, em alguns casos" (DALEY, 2010, p. 483). Vejamos alguns exemplos, com grifos nossos, que comprovam o letramento visual nas práticas exercidas por elaboradores de material didático para o ensino on-line:

5. [...] se um aluno está com o conteúdo de literatura e de repente ele tem a possibilidade de entrar em imagens de museus europeus em que aparecem formas pictóricas do mesmo tempo em que apareceu aquele texto literário, isso é uma informação em que as gerações anteriores não tinham (PROF 1).

6. Como a gente sabe, o material que vai para a web ou mesmo o que vai impresso são materiais imagéticos, são materiais que recorrem bastante ao uso de imagens, fotografias, outras linguagens. [...] Para mim, a figura é mais um texto para construir um sentido. Então a figura não é uma mera ilustração. A figura é parte constitutiva do texto. Como é que eu sei se ela é ilustrativa? Se você tem um material que você tira do texto, então é ilustrativo (PROF 3).

Os professores conteudistas, ao mencionarem que precisam fazer uso de imagens de um museu para incrementar o conteúdo de literatura ou ainda refletirem sobre a função da imagem no material que produzem para o curso on-line, nos remonta a Ron Bleed, para quem, "no século 21, a capacidade de interpretar e criar meios visuais, digitais e de áudio tem se tornado uma forma de letramento tão básica como a leitura e escrita de textos verbais" (BLEED, 2005, p. 3, tradução nossa).

Observemos, na FIG. 3, parte de um tópico de aula, elaborado para ser disponibilizado no Solar, no qual o aluno só entenderá o conteúdo se visualizar as imagens, pois os professores conteudistas estão reconhecendo o poder dos novos letramentos e a educação, mesmo a presencial, deve se pautar pelo ensino dos múltiplos letramentos. 


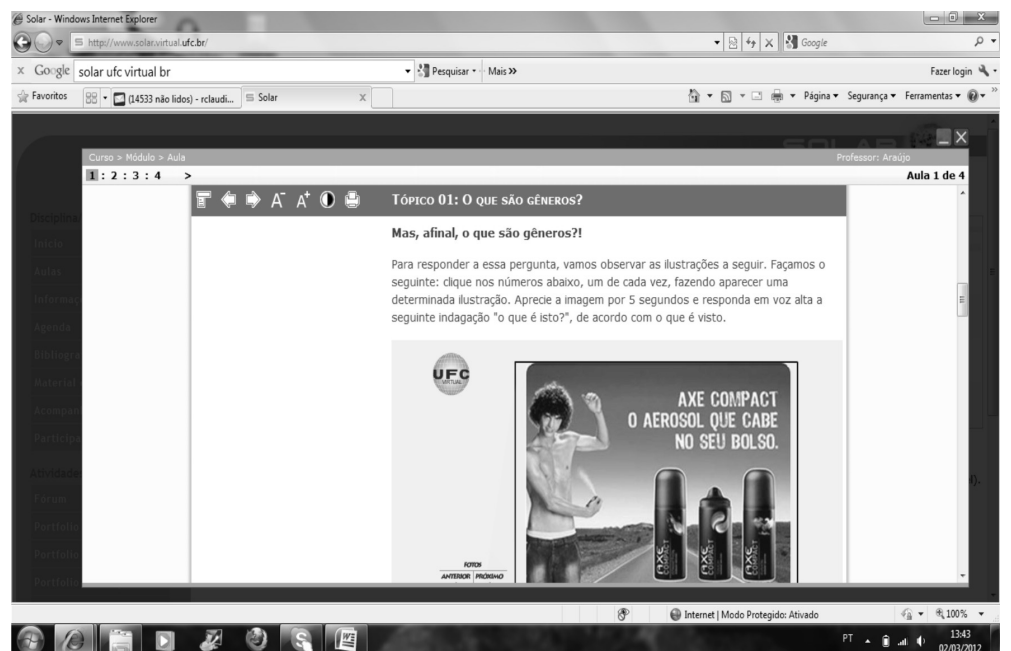

FIGURA 3 - Início do tópico “O que são gêneros”, retirado da disciplina Gêneros Textuais e Ensino

A figura corrobora o que Semalli defende para o letramento visual. Para esse autor o referido letramento custodia "múltiplas habilidades de ler, ver, compreender, avaliar e interpretar os textos visuais, incluindo artefatos, imagens, desenhos ou pinturas que representam um evento, ideia ou emoção" (SEMALLI, 2001, tradução nossa). Nesse sentido, o conteúdo revelado na FIG. 3 mostra que, ao fazer uso de expressões como "clique" ou "aprecie a imagem", o professor conteudista não apenas domina esses letramentos como também compreende que seus alunos também farão uso dessas habilidades. Percebemos também que ensinar e aprender em ambientes virtuais é entrelaçar, ao letramento visual, tantos outros letramentos, como o tradicional, o tecnológico etc. Esse aspecto também é observado por Snyder, para quem

em um mundo eletronicamente mediado, ser letrado tem a ver com a compreensão de como as diferentes modalidades semióticas são combinadas de forma complexa para criar significado. As pessoas precisam aprender a construir sentido em relação aos sistemas de ícones presentes nas telas de computador - com todas as combinações de signos, símbolos, imagens, palavras e sons. (SNYDER, 2002, p. 3, tradução nossa).

Assim, para exercer práticas de letramento visual, o usuário também possui certo nível de outros letramentos, formando, desse modo, uma mescla de letramentos para compreensão das mensagens. 


\section{Letramento informático}

No Brasil, as tecnologias de informação e comunicação foram inseridas no ensino após estarem presentes nos diversos setores sociais, tais como bancos, empresas etc. Assim, ao adentrarem a escola, houve, inicialmente, uma resistência por parte dos professores por acreditarem que essa ferramenta iria substituir os docentes. No entanto, conforme relata o documento que avalia os letramentos de alunos nos Estados Unidos, o uso dos computadores na educação evoluiu rapidamente do computador como professor para computador como ferramenta (USA, 2009). O referido documento considera educadores letrados tecnologicamente aqueles profissionais que, estando atentos às mudanças educacionais, auxiliam os estudantes a desenvolver habilidades para usar computadores, redes de informação, mídia digital e outras tecnologias de informação, considerando seus objetivos de aprendizagem.

Essas habilidades apontam para o que Semalli (2001) denomina de letramento informático. Essa categoria de letramento também foi identificada em nossos dados, pois ela está bastante presente nas práticas dos professores conteudistas e da equipe de transição didática do Curso de Letras semipresencial da UFC em parceria com a Universidade Aberta do Brasil (UAB). As atividades que consideramos como indicativos de letramento informático dizem respeito ao uso e à execução de tarefas relacionadas com a linguagem do computador, já que elas exigem competências alusivas às representaçōes visuais, multimidiáticas, interativas e hipertextuais. Sendo assim, para produção do material didático, os usufrutuários devem ter habilidades com os softwares, para que se aproveitem as possibilidades que as tecnologias de informação e comunicação oferecem para interação homem-homem ou homem-máquina, conforme ilustramos com os excertos seguintes, com grifos nossos:

7. Quando o professor já tem hábito de mexer com tecnologia, ele já sabe mais ou menos onde cabe cada coisa (TD 1).

8. [...] tem professor que já prepara a aula pensando na web. (TD 2).

9. [...] temos sensibilidade para o fato de que o aluno vai utilizar ao máximo os recursos da rede. [...] Então eu faço uma previsão de tudo que épossivel, pelo menos dentro das nossas possibilidades. (PROF 1).

10. Sem dúvida nenhuma eu diria que o processo se assemelha a uma alfabetização. Então uma pessoa que não está acostumada a utilizar o universo dessas midias, sobretudo de redes e se depara de repente com a necessidade de projetar um bate papo, um fórum e controlar isso e 
receber as comunicaçôes dos alunos, é evidentemente que ele vai entrar numa situação de desespero, e isso em termos de uso prático. Agora, ao elaborar o material é evidente que ele vai tender a trazer uma linguagem que fica muito aquém das possibilidades de exploração didática através desse meio. (PROF 1).

Os dados, mais uma vez, confirmam que os professores conteudistas, cada vez mais, dominam múltiplos letramentos no processo de elaboração dos conteúdos para as disciplinas que coordenam na graduação on-line. Se projetar um chat ou um fórum ainda representa para alguns um desafio quase instransponível, está cada vez mais claro que escrever hipertextos pedagógicos é uma prática que exige um letramento especial, aqui denominado de letramento hipertextual, o qual é o resultado da intersecção entre letramentos múltiplos.

No caso dos cursos on-line, o aluno também deve possuir habilidades mínimas com a linguagem computacional para uma melhor interação no ambiente. Observando o ambiente virtual desenvolvido pela UFC, percebemos que, nos cursos ofertados pela UFC Virtual, através da plataforma Solar, há orientaçôes de como navegar e acompanhar todo material disponibilizado, conforme mostra o seguinte exemplo:

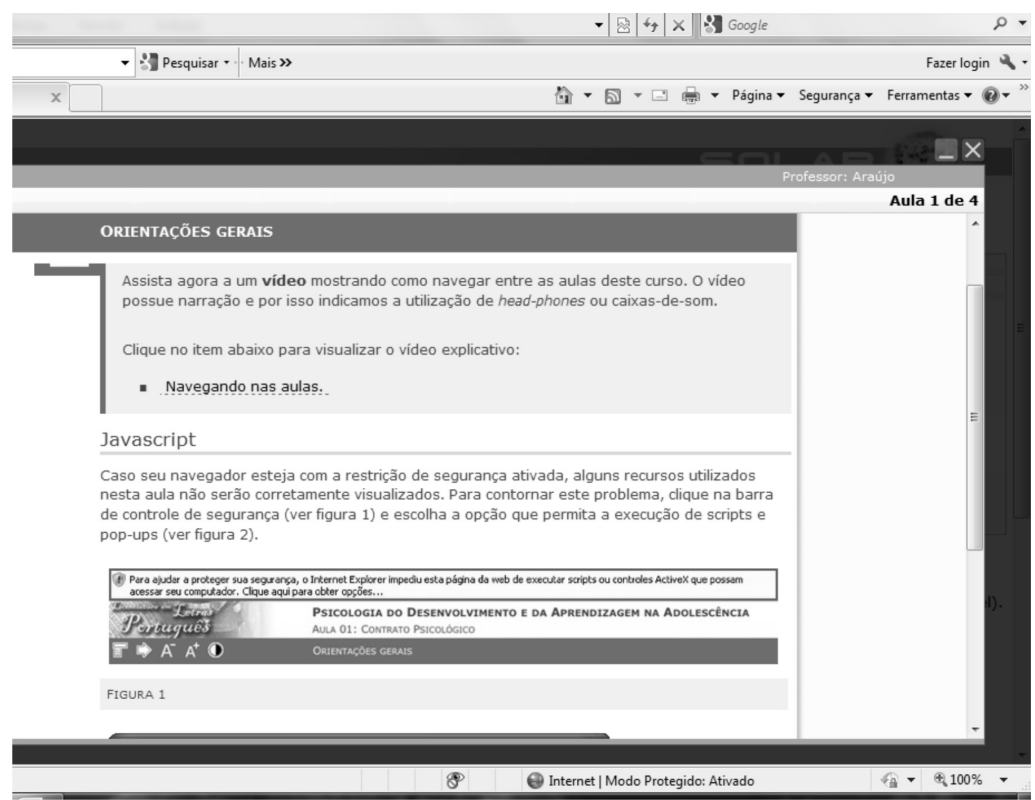

FIGURA 4 - Orientações gerais, disponibilizadas em todas as disciplinas do Instituto UFC Virtual 
A FIG. 4 confirma a declaração de Berger, para quem, no contexto dos letramentos digitais, a navegação envolve:

mais do que a simples capacidade de usar o software ou operar um dispositivo digital, pois uma variedade de técnicas, habilidades cognitivas, sociais e emocionais são incluídas pelos usuários que entendem esses fatores como imprescindíveis para a interação funcionar efetivamente em um ambiente digital. (BERGER, 2007, p. 1, tradução nossa).

Esses atributos podem auxiliar os estudantes no desenvolvimento de um conjunto sofisticado de habilidades para navegar pelas estruturas de informação nos conteúdos digitais, a fim de encontrar o que precisam. Aliás, encontrar e saber usar a informação certa é outro letramento subjacente à tarefa de elaboração do conteúdo pelos professores.

\section{Letramento informacional}

O termo letramento informacional, surgido nos Estados Unidos, na década de 1970, apareceu em trabalhos da área de biblioteconomia e referiase, inicialmente, às competências e "habilidades ligadas ao uso da informação eletrônica”. Desde então, os estudos sobre o assunto se multiplicaram naquele país e seu conceito, naturalmente, vem se modificando com as transformaçóes sociais. No Brasil, ainda não são muitos trabalhos relacionados a esse tema, porém, o termo foi mencionado pela primeira vez por Sônia Elisa Caregnato, em 2000, que o traduziu por 'alfabetização informacional' e refletia sobre as mudanças que as bibliotecas deveriam enfrentar para desenvolver nos alunos habilidades para lidar com o ambiente digital. Atualmente, os pesquisadores brasileiros concordam com o fato de a necessidade das bibliotecas ampliarem suas funçôes pedagógicas, adequando-se a um novo paradigma educacional e os bibliotecários repensarem seu papel (CAMPELLO, 2003, p. 28-29).

Nos Estados Unidos, muitos estudos resultaram em documentos e foram publicados, destacando-se o Information Power que, segundo Bernadete Campello, "concretiza a assimilação do conceito de competência informacional pela classe bibliotecária" (CAMPELLO, 2003, p. 31). Neste documento, conforme a referida autora, descreve-se um conjunto de habilidades informacionais que devem ser desenvolvidas nos alunos, divididas em três grupos.

No primeiro grupo, requer-se competência informacional do aluno. Assim, este deve ter essa competência para acessar a informação de forma eficiente e efetiva, avaliando-a crítica e competentemente e usando-a com 
precisão e criatividade. Em nossa pesquisa, descobrimos que os professores, na elaboração do material didático, possuem essa competência, pois ao fazer previsão do material existente na web, eles precisam buscar e acessar as informaçõos antes de publicá-lo. Vejamos a declaração de um dos participantes no trecho a seguir (grifos nossos):

11. Então eu faço uma previsão de tudo que épossivel, pelo menos dentro das nossas possibilidades, de aconselhamento para que o aluno pesquise através de ligações... de links com bibliotecas com material externo (PROF 1).

O segundo grupo de competências informacionais diz respeito à aprendizagem independente, a qual requer que o discente tenha essa capacidade para aprender com independência, obtendo excelência na informação pesquisada e no conhecimento relacionado aos seus interesses pessoais e apreciando literatura e outras formas criativas de expressão da informação. Essa competência também foi observada nos participantes de nossa pesquisa, como vemos nos exemplos (12) e (13). Percebemos também a compreensão do professor em despertar no aluno essa aprendizagem independente, conforme exemplo (14), também com grifos nossos:

12. Eu fiz muito mais foi um conjunto de perguntas e uma coletânea bastante grande de apoio para eles consultarem sobre o que é uma didática, por exemplo, na área de literatura, que questões dos direitos humanos eles se ligam a literatura no conceito de Antônio Candido, por exemplo (PROF 1).

13. Então o virtual obriga a uma autonomia, o aluno se realmente não se esforçar ele acaba desistindo (PROF 1).

14. No entanto, jamais roubar do aluno o prazer de chegar ao texto literário, de se aprofundar, inclusive pesquisar fontes, por exemplo, artigos que nós colocamos a disposição, teses... muitas vezes, para que ele possa fazer um aprofundamento (PROF 1).

Outra competência requerida no documento é a responsabilidade social a qual requer que o aluno contribua positivamente para a comunidade de aprendizagem e para a sociedade, participando efetivamente de grupos, a fim de buscar e gerar informação, através de comportamento democrático e ético. Nesse sentido, percebemos, no seguinte trecho, a consciência ética dos direitos autorais pelo participante da pesquisa (grifo nosso): 
15. às vezes, quando é evidentemente legalmente permitido, eu trago para o ambiente para que ele possa utilizar na forma, por exemplo, de PDF (PROF 1).

Elisabeth A. Dudziak (2003) também analisa a necessidade de estudos que priorizem o information literacy ${ }^{3}$ e afirma que manter-se informado é uma necessidade para atuar na sociedade e, atualmente, essa necessidade encontra barreiras, haja vista a ampla e caótica disponibilização de informações, principalmente via internet. Segundo a autora, a educação deve ser voltada para a information literacy, pois o aprendizado deve ser permanente.

No contexto do ensino a distância, é necessário prover o material didático de pistas que ajudem os alunos a conquistarem altos níveis de letramento informacional, sobretudo porque, segundo mostra Ilene F. Rockman,

Os estudantes universitários podem até ter ler, escrever e enviar e-mails, conversar em chats, baixar músicas, mas muitos ainda não aprenderam a localizar eficazmente informações, avaliar, sintetizar e integrar ideias; muitos não sabem utilizar as informações em um trabalho original ou dar crédito apropriado para informação utilizada. (ROCKMAN, 2004, p. 10, tradução nossa).

Assim, participando de um curso de graduação on-line, todos os agentes, sejam eles professores, tutores, alunos etc., devem estar conscientes dos desafios de gerir adequadamente a informação que marca a web. Uma das maneiras encontradas pelos professores conteudistas foi disponibilizar material de apoio por meio de links ou de compartilhar arquivos em PDF, como ilustra a FIG. 5.

\footnotetext{
${ }^{3}$ Dudziak (2003) preferiu referir-se ao termo em inglês, afirmando que a expressão ainda não possui uma tradução e porque no seu artigo esse não era seu objetivo.
} 


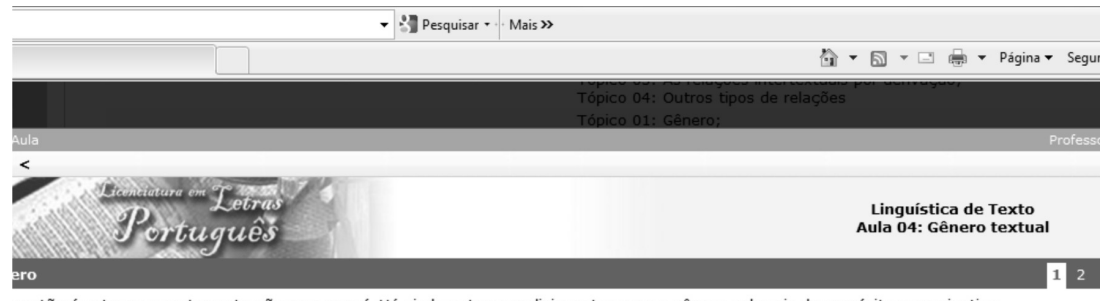

uestão é extensa e certamente não para por aí. Há ainda outras condicionantes para o gênero, ademais do propósito comunicativo.

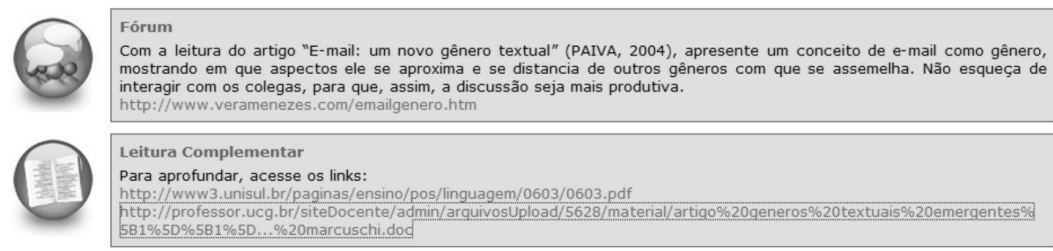

ências - (Clique aqui)

FIGURA 5 - Atividade de fórum e leitura indicando letramento informacional do professor

A decisão por compartilhar bons artigos em PDF e indicar sites, academicamente, confiáveis no conteúdo elaborado é um importante indicativo de que o professor não só domina o letramento informacional como também compreende a relevância de fornecer esse letramento aos seus alunos; afinal, como demonstra Rockman (2004), alguns estudantes universitários, muitas vezes, carentes de fontes de informação importantes, não fazem distinções entre obras eruditas e populares e, em função disso, tendem a abraçar a web como uma biblioteca tradicional. Como resultado, os estudantes podem correr o risco de aceitar qualquer informação que é exibida a partir de um site de busca, como o Google, dando maior valor às fontes de corrente de informação do que às mais aprofundadas discussóes que, muitas vezes, são encontradas em importantes periódicos ou em livros.

\section{Considerações finais}

Nas práticas dos usuários dos Cursos de Licenciatura em Letras Português e Licenciatura em Letras - Espanhol, percebemos que são demandados diversos letramentos, como tradicional, visual, informático e informacional. Constatamos ainda que há um entrelaçamento desses letramentos, pois, em muitos casos, a compreensão dos sentidos só é realizada se o usuário possuir mais de um letramento. Porém, para produção e elaboração de hipertextos, não é necessário que todos esses letramentos sejam praticados em uma única interação. 
Desse modo, é fácil constatar que a fusão de variadas modalidades nem sempre é harmônica, pois dependendo da natureza do hipertexto, uma modalidade semiótica ou outra ganha destaque. Também com relação ao letramento hipertextual, afirmamos que, no entrelaçamento de usos sociais que concorrem para esse tipo de letramento, um ou outro pode ganhar destaque, dependendo de diversos aspectos, tais como objetivo do usuário ou do hipertexto, maneira como o hipertexto foi distribuído etc. (LOBO-SOUSA; PINHEIRO; ARAÚJO, 2009, p. 114). Assim, em se referindo aos cursos on-line, até mesmo nas academias, que são consideradas comunidades discursivas mais inflexíveis com relação às práticas de escrita, percebemos que essa modalidade deixou de ser a única âncora que sustenta o barco das práticas letradas de seus agentes.

Subjacente ao processo de elaboração do material didático disponibilizado para o Curso de Letras Semipresencial da UFC-UAB, de onde extraímos os dados analisados neste artigo, há um entrelaçado de letramentos múltiplos que se manifesta através de práticas entrecruzadas de linguagens multimodais. A elaboração desses conteúdos hipertextuais exige dos professores e da equipe de transição didática, portanto, o que denominamos aqui de letramento hipertextual, cuja base se localiza na intersecção de diversos letramentos, pois essa atividade reclama dos usuários destrezas que vão muito além do letramento tradicional. Desse modo, conforme Lemke (2010), toda prática letrada de construção de significado estabelece relação de interdependência com habilidades que vão desde a navegação no teclado até a virada de uma página (no caso das tecnologias impressas).

\section{Referências}

BARTON, D.; HAMILTON, M.; IVANIÈ, R. Situated Literacies. London: Routledge, 2000.

BERGER, P. Learning in the Web 2.0 World. 2007. Disponível em: <http:// infosearcher.typepad.com/infosearcher/2007/04/learning_in_the.html>. Acesso em: 1 out. 2011.

BLEED, R. Visual Literacy in Higher Education. Educause Learning Initiative - ELI Explorations, ago. 2005. Disponível em: <http://www.educause.edu/ LibraryDetailPage/666?ID=ELI4001>. Acesso em: 1 out. 2011.

BOLTER, J. D. Hypertext and the Question of Visual Literacy. In: REINKING, D.; McKENNA, M. C.; LABBO, L. D.; KIEFFER, R. D. Handbook of Literacy and Technology: Transformations in a Post-Typographic World. New Jersey; London: Lawrence Erlbaum Associates, 1998. 
CAMPELLO, B. O movimento da competência informacional: uma perspectiva para o letramento informacional. Ciência da Informação, Brasília, v. 32, n. 3, p. 28-37, 2003.

CAREGNATO, S. E. O desenvolvimento de habilidades informacionais: o papel das bibliotecas universitárias no contexto da informação digital em rede. Revista de Biblioteconomia \& Comunicação, Porto Alegre, v. 8, p. 47-55, 2000.

CAVALCANTE JUNIOR, F. S. Por uma escola do sujeito: o método (con)texto de letramentos múltiplos. 2. ed. Fortaleza: Demócrito Rocha, 2003.

CERUTTI-RIZZATTI, M. E. Letramento: um conceito em (des)construção e suas implicações/repercussões na ação docente em língua materna. Fórum Linguistico, Florianópolis, v. 6, n. 2, p. 1-15, jul.-dez. 2009.

CRYSTAL, D. A revolução da linguagem. Rio de Janeiro: Jorge Zahar, 2005.

DALEY, E. Expandindo o conceito de letramento. Trabalhos em Linguistica Aplicada, Campinas, v. 49, n. 2, p. 481-491, jul.-dez. 2010.

DUDZIAK, E. A. Information literacy: princípios, filosofia e prática. Ciência da Informação, Brasília, v. 32, n. 1, p. 23-35, 2003.

FOLTZ, P. W. Comprehension, Coherence, and Strategies in Hypertext and Linear Text. In: ROUET, J. F. et al. Hypertext and Cognition. New Jersey: Lawrence Erlbaum Associates, 1996. p. 109-136.

LANDOW, G. P. Hipertexto: la convergencia de la teoría crítica contemporánea y la tecnología. Paidós: Barcelona; Buenos Aires; México (DF), 2002.

LEMKE, J. L. Letramento metamidiático: transformando significados e mídias. Trabalhos em Linguistica Aplicada, Campinas, v. 49, n. 2, p. 455-479, jul.-dez. 2010.

LEMKE, J. L. Travels in Hypermodality. Visual Communication, London, v. 1, n. 3, p. 299-325, 2002.

LOBO-SOUSA, A. C.; PINHEIRO, R. C.; ARAÚJO, J. C. Letramentos que emergem da hipertextualidade. In: ARAÚJO, J. C.; DIEB, M. (Org.). Letramentos na web: gêneros, interação e ensino. Fortaleza: Edições UFC, 2009. p. 111-122.

MARCUSCHI, L. A. O hipertexto como um novo espaço de escrita em sala de aula. In: AZEREDO, J. C. (Org.). Lingua Portuguesa em Debate. Petrópolis: Vozes. p. 87-111, 2000.

PINHEIRO, R. C. Estratégias de leitura para compreensão de hipertextos. In: ARAÚJO, J. C.; BIASI-RODRIGUES, B. (Org.). Interação na internet: novas formas de usar a linguagem. Rio de Janeiro: Lucerna, 2005. p. 131-146. 
ROCKMAN, I. F. Introduction: The Importance of Information Literacy. In: ROCKMAN, I. F. et al. (Ed.). Integrating Information Literacy in the Higher Education Curriculum: Practical Models for Transformation. Jossey Bass: New York, p. 1-28, 2004. Disponível em: <http://media.wiley.com/product_data/ excerpt/78/07879652/0787965278.pdf>. Acesso em: 1 mar. 2012.

SEMALLI, L. Defining New Literacy in Curricular Practice. Reading On-Line, v. 5, n. 4, nov. 2001. Disponível em: <http://www.readingonline.org/ newliteracies/lit_index.asp?HREF=semali1/index.html>. Acesso em: 1 maio 2010 .

SNYDER, I. (Ed.). Silicon Literacies: Communication, Innovation, and Education in the Electronic Age. London: Routledge, 2002.

SOARES, M. Letramento: um tema em três gêneros. 2. ed. Belo Horizonte: Autêntica, 2000.

STREET, B. V. Literacy in Theory and Practice. Cambridge (MA): CUP, 1984.

STREET, B. V. What's "New" in New Literacy Studies? Critical Approaches to Literacy in Theory and Practice. Current Issues in Comparative Education, v. 5, n. 2, p. 77-91, 2003. Disponível em: <http://www.tc.columbia.edu/cice/ archives/5.2/52street.pdf>. Acesso em: 1 set. 2008.

USA. Assessment Development Committee. Technological Literacy Framework for the 2012 National Assessment of Educational Progress. WestEd, 2009 (Discussion Draft - 24 jul. 2009). Disponível em: <http://www.docstoc.com/ docs/11386736/Draft-Technological-Literacy-for-NAEP>. Acesso em: $1 \mathrm{fev}$. 2011.

Recebido em 15/03/2012. Aprovado em 25/06/2012. 